\title{
Ezetimibe suppresses cholesterol accumulation in lipid-loaded vascular smooth muscle cells in vitro via MAPK signaling
}

\author{
Li QIN', 2, \#, Yun-bo YANG ${ }^{1,3,4, \# \text {, Yi-xin YANG }}{ }^{3}$, Neng ZHU ${ }^{4,5}$, Yong-zhen GONG ${ }^{1,6}$, Cai-ping ZHANG ${ }^{2}$, Shun-xiang LI $^{1}$, \\ Duan-fang $\mathrm{LIAO}^{1, *}$ \\ ${ }^{1}$ Division of Stem Cell Regulation and Application, School of Pharmacy, Hunan University of Chinese Medicine, Changsha 410208, \\ China; ${ }^{2}$ Institute of Pharmacy and Pharmacology, South China University, Hengyang 421001, China; ${ }^{3}$ Matthew Mailing Centre for \\ Translational Transplantation Studies, London Health Sciences Centre, Western University, London N6A5A5, Canada; ${ }^{4}$ The Second \\ Xiang-Ya Hospital, Central South University, Changsha 410011, China; ${ }^{5}$ The Second Affiliated Hospital, South China University, \\ Hengyang 421001, China; ${ }^{6}$ Department of Pharmacology, Central South University, Changsha 410011, China
}

Aim: To investigate the mechanisms of anti-atherosclerotic action of ezetimibe in rat vascular smooth muscle cells (VSMCs) in vitro. Methods: VSMCs of SD rats were cultured in the presence of Chol:MßCD $(10 \mu \mathrm{g} / \mathrm{mL})$ for $72 \mathrm{~h}$, and intracellular lipid droplets and cholesterol levels were evaluated using Oil Red O staining, HPLC and Enzymatic Fluorescence Assay, respectively. The expression of caveolin-1, sterol response element-binding protein-1 (SREBP-1) and ERK1/2 were analyzed using Western blot assays. Translocation of SREBP-1 and ERK1/2 was detected with immunofluorescence.

Results: Treatment with Chol:MBCD dramatically increased the cellular levels of total cholesterol (TC), cholesterol ester (CE) and free cholesterol (FC) in VSMCs, which led to the formation of foam cells. Furthermore, Chol:M $\beta C D$ treatment significantly decreased the expression of caveolin-1, and stimulated the expression and nuclear translocation of SREBP-1 in VSMCs. Co-treatment with ezetimibe (3 $\mu \mathrm{mol} / \mathrm{L}$ ) significantly decreased the cellular levels of TC, CE and FC, which was accompanied by elevation of caveolin-1 expression, and by a reduction of SREBP-1 expression and nuclear translocation. Co-treatment with ezetimibe dose-dependently decreased the expression of phosphor-ERK1/2 (p-ERK1/2) in VSMCs. The ERK1/2 inhibitor PD98059 (50 $\mu$ mol/L) altered the cholesterol level and the expression of $\mathrm{p}-\mathrm{ERK} 1 / 2$, SREBP-1 and caveolin-1 in the same manner as ezetimibe did.

Conclusion: Ezetimibe suppresses cholesterol accumulation in rat VSMCs in vitro by regulating SREBP-1 and caveolin-1 expression, possibly via the MAPK signaling pathway.

Keywords: atherosclerosis; vascular smooth muscle cells; cholesterol; ezetimibe; caveolin-1; SREBP-1; MAPK

Acta Pharmacologica Sinica (2014) 35: 1129-1136; doi: 10.1038/aps.2014.10; published online 4 Aug 2014

\section{Introduction}

Together, cardiovascular diseases (CVDs) such as atherosclerosis and stroke remain the leading cause of death worldwide. Numerous studies have indicated that excessive accumulation of vascular smooth muscle cells (VSMCs) has a preferential role in the development and progression of atherosclerosis. Cholesterol accumulation in VSMCs and monocytes/macrophages leads to the formation of lipid-loaded cells or foam cells, which is a pathological feature of atherosclerosis ${ }^{[1]}$.

\footnotetext{
\# These authors contributed equally to this work.

* To whom correspondence should be addressed.

E-mail dfliao66@aliyun.com

Received 2013-11-20 Accepted 2014-07-14
}

Ezetimibe is a potent inhibitor of the intestinal absorption of cholesterol and is widely used for the treatment of hypercholesterolemia in humans ${ }^{[2,3]}$. More recently, ezetimibe has been reported to possess pleiotropic effects beyond cholesterol lowering both in vitro and in animal models ${ }^{[4]}$. The beneficial effect of ezetimibe on the development of atherosclerosis was first shown in apolipoprotein E-deficient mice fed with a highfat diet ${ }^{[5]}$. Similarly, ezetimibe reduced atherosclerotic lesion formation in a diet-induced atherosclerosis model in hypercholesterolemic rabbits ${ }^{[6]}$. However, the exact anti-atherosclerotic mechanism of ezetimibe remains to be elucidated.

Caveolin-1 (Cav-1) is a 22-kDa protein that forms the main structure of caveolae ${ }^{[7]}$ and is believed to play a crucial role in the regulation of cellular signaling and cholesterol transport ${ }^{[8]}$. 
The established Cav-1 knockout mouse line has confirmed the importance of Cav-1 for the formation of morphologically distinct caveolae ${ }^{[9,10]}$. In addition, Cav-1 is also involved in the maintenance of cellular cholesterol homeostasis and lipid transport. An increasing number of studies have demonstrated that caveolae and Cav-1 expression are associated with enhancement of cholesterol efflux ${ }^{[11,12]}$, which contributes to the inhibition of cholesterol accumulation. Smart et al found that the Cav-1 and Annexin-2 complex is a target of ezetimibe in the regulation of intestinal cholesterol transport ${ }^{[13,14]}$, and ezetimibe therapy has been shown to downregulate SREBP-1 and SREBP-2 expression ${ }^{[15,16]}$.

It is evident that SREBP-1 exists in the cytoplasm and nucleus and is associated with cholesterol metabolism ${ }^{[17]}$. Its active form can translocate into the nucleus and regulate target gene transcription through binding with the sterol regulatory element (SRE) sequence within target gene promoters ${ }^{[18,19]}$. Interestingly, an SRE sequence exists in the Cav-1 promoter, and Cav-1 is negatively regulated by SREBP-1 ${ }^{[19,20]}$. A previous study showed that SREBP expression can be regulated by ezetimibe and is associated with cholesterol transport and metabolism ${ }^{[21]}$. Recently, accumulating evidence has shown that SREBPs are not only participants in cholesterol-regulated events but are also gene regulatory targets of intracellular signaling pathways, such as MAP kinase cascades that are associated with cholesterol transport ${ }^{[22]}$. More importantly, MAP kinase-mediated effects on SREBP-1-regulated target genes are linked to the phosphorylation site of MAP kinaseits phosphorylation site ${ }^{[23]}$.

The purpose of this study was to address the underlying mechanism of ezetimibe-dependent effects on cholesterol accumulation in cultured VSMCs. We hypothesized that ezetimibe exerted beneficial effects on atherosclerosis partially through regulating the expression of Cav-1 and SREBP-1 via the MAPK pathway, subsequently inhibiting cellular cholesterol accumulation.

\section{Materials and methods Reagents}

Dulbecco's modified Eagle's medium (DMEM) and fetal bovine serum (FBS) were purchased from Gibco/BRL (Grand Island, NY, USA). Ezetimibe was purchased from Merck/ Schering-Plough Pharmaceuticals $(0.021 \%, w / w)$ and Oil Red O powder was obtained from Sigma-Aldrich (St Louis, MO, USA) and dissolved with DMSO (Sangon, Shanghai, China). All reagents were of analytical grade.

\section{Isolation and culture of VSMCs}

Primary VSMCs were derived from the thoracic aorta of adult male Sprague-Dawley (SD) rats as described previously ${ }^{[24,25]}$. Rat aortic VSMCs were isolated from the thoracic aortas of sixweek-old male SD rats using the explant technique ${ }^{[26]}$. Briefly, after the removal of the endothelium and adventitia, the aortic explants were cultured in DMEM containing 20\% FBS. Within 9-10 d, VSMCs migrating from explanted vessels were evident. Cells growing in DMEM containing 10\% FBS were used at low passage numbers (కten passages).

\section{Cellular cholesterol assay (Oil Red 0 staining)}

Foam cell formation was verified by fixation with $4 \%$ paraformaldehyde and subsequent staining with $0.5 \%$ Oil Red $\mathrm{O}$. Hematoxylin was used as a counterstain, and the cells were photographed at $400 \times$ magnification.

\section{Quantitation of intracellular cholesterol (HPLC and Enzymatic Fluorescence Assay)}

Cellular free cholesterol (FC) and total cholesterol (TC) were analyzed by HPLC ${ }^{[27]}$. Briefly, cells were placed in $0.9 \% \mathrm{NaCl}$ solution and homogenized on ice by sonication for $10 \mathrm{~s}$. After the protein concentration was measured with the bicinchoninic acid (BCA) assay (Pierce Biotechnology Company, Rockford, IL, USA), an equal volume of freshly prepared cold $\left(-20^{\circ} \mathrm{C}\right)$ potassium hydroxide in ethanol $(150 \mathrm{~g} / \mathrm{L})$ was added to the cell lysate and vortexed until clear. An equal volume of hexane isopropanol $(3: 2, v / v)$ was added and vortexed for 5 min followed by centrifugation at $800 \times g$ for $5 \mathrm{~min}$. The organic phases were collected and dried in a SpeedVac. The samples were dissolved in $100 \mu \mathrm{L}$ isopropanol-acetonitrile $(20: 80, v / v)$ and placed in an ultrasound water bath at room temperature for $5 \mathrm{~min}$. Finally, the samples were subjected to HPLC analysis (Agilent 1100, Agilent Technology, USA). HPLC was performed on a Hypersil-C18 column, and elution was performed with an isopropanol:acetonitrile $(20: 80, v / v)$ solvent system at a flow rate of $1 \mathrm{~mL} / \mathrm{min}$. Cholesterol ester (CE) was determined by subtracting the FC values from the TC values ${ }^{[19]}$.

Another method was to use Cholestero Quantitation Kit (Catalogue No. K603-100, Biovision, Inc, Mountain View, CA, USA). Cells $\left(1 \times 10^{6}\right)$ were extracted with $200 \mu \mathrm{L}$ of chloroform: isopropanol: NP-40 (7:11:0.1) in 1.5 mL EP, and then cell membrane was destructed by ultrasonic, the extract was spun at $15000 \times g$ for $10 \mathrm{~min}$. The liquid was transferred to a new tub, air dried at $50^{\circ} \mathrm{C}$ for $4 \mathrm{~h}$ to remove chloroform. The samples were put under vacuum at $50^{\circ} \mathrm{C}$ for $30 \mathrm{~min}$ to remove trace organic solvent. The dried lipids were dissolved with 200 $\mu \mathrm{L}$ Cholesterol Assay buffer, $20 \mu \mathrm{L}$ for Cholesterol Quantitation following the protocols provided by the manufacturer. Contents of cholesterol was measured by fluorescence at Ex/ $E m=535 / 590$. Protein concentrations were determined by the BCA $^{\text {TM }}$ Protein Assay Kit according to the protocol provided by the manufacturer (Catalogue No P0012, Beyotime, Inc, Haimen, China). The values of intracellular cholesterol were calculated as $\mu \mathrm{g}$ cholesterol/ $\mu \mathrm{g}$ cellular protein.

\section{Immunofluorescence staining}

For immunofluorescence analysis ${ }^{[28]}, 2 \times 10^{5}$ cells were plated into each well of a 6-well plate with coverslips. The cells were incubated with $10 \mu \mathrm{g} / \mathrm{mL}$ Chol:M $\beta C D$ in the presence or absence of $3 \mu \mathrm{mol} / \mathrm{L}$ ezetimibe for $72 \mathrm{~h}$. After the treatment, the cells were washed with PBS. Then, the cells were fixed with $4 \%$ paraformaldehyde for $10 \mathrm{~min}$. All fixed cells were permeabilized in $0.1 \%$ Triton $\mathrm{X}-100$ for $10 \mathrm{~min}$. The cells were incubated with SREBP-1 antibody for $60 \mathrm{~min}$ at room tempera- 
ture. Next, the cells were incubated with rhodamine-conjugated anti-rabbit IgG for $30 \mathrm{~min}$ and subsequently incubated with DAPI (10 $\mathrm{gg} / \mathrm{mL})$ (Sigma, USA) for $10 \mathrm{~min}$ to display the cell nuclei. Coverslips were mounted and analyzed by fluorescence microscopy.

\section{Western blot analyses}

Western blot analysis was performed as previously described $^{[24,29,30]}$. Briefly, cells were lysed in a buffer containing $10 \mathrm{mmol} / \mathrm{L}$ HEPES (pH 7.9), $1.5 \mathrm{mmol} / \mathrm{L} \mathrm{MgCl}_{2}$, $10 \mathrm{mmol} / \mathrm{L} \mathrm{KCl}$ and $0.5 \% \mathrm{NP}-40$, and the cell lysates were centrifuged at $13000 \mathrm{r} / \mathrm{min}$ for $15 \mathrm{~min}$ at $4{ }^{\circ} \mathrm{C}$. The protein concentrations of the cell lysates were determined using a BCA protein assay kit according to the manufacturer's instructions. The proteins were separated on 6\%-10\% SDS-PAGE and transferred to a polyvinylidene difluoride membrane (Millipore Corporation, Billerica, MA, USA). Nitrocellulose membranes were incubated in blocking solution [PBS with $0.05 \%(v / v)$ Tween 20 (PBST) containing 5\% (w/v) skim milk or $1 \%(w / v)$ BSA (Sigma-Aldrich)] for $1 \mathrm{~h}$ at room temperature to block nonspecific binding. The blot was incubated overnight with anti-apoE (Santa Cruz Biotechnology, USA), anti-SR-B1 (Abcam, USA), anti-Cav-1, anti-CD36 (Santa Cruz Biotechnology, USA), anti-p-ERK1/2 and anti-T-ERK1/2 (Cell Signaling Technology, Danvers, MA, USA) or anti-a-tubulin (Santa Cruz Biotechnology, USA) primary antibodies in blocking solution. The blot was washed 3 times for $10 \mathrm{~min}$ each in PBST at room temperature, incubated for 45 min in speciesappropriate horseradish peroxidase-conjugated secondary antibody (Sigma, St Louis, MO, USA) in blocking solution, and subsequently washed 3 times in PBST. Specific proteins were visualized using an Enhanced Chemiluminescence Kit (New England Biolabs, Beverly, MA, USA).

\section{mRNA extraction and real-time quantitative PCR (RT-qPCR)}

Total RNA was prepared using an RNeasy Mini Kit, and $2 \mu \mathrm{g}$ was reverse transcribed using a QuantiTect Reverse Transcription Kit with Oligo dT as a primer. RT-qPCR was carried out using target gene primers with the SYBR Green PCR master mix (Applied Biosystems, Warrington, UK). The following primers were used: $\beta$-actin forward primer: 5'-CCCTGTACGCCAACACAGTGC-3'; $\beta$-actin reverse primer: 5'-ATACTCCTGCTTGCTGATCC-3'; Cav-1 forward primer: 5'-ATGTCTGGGGGCAAATACGTG-3', Cav-1 reverse primer: 5'-CGCGTCATACACTTGCTTCT-3'. For SREBP-1, 5'-TGCCCTAAGGGTCAAAACCA-3' and 5'-TGGCGGGCACTACTTAGGAA-3' served as the forward and reverse primers, respectively. Quantitative measurements were determined using the $\Delta \Delta \mathrm{Ct}$ method, and average mRNA expression was normalized to $\beta$-actin expression.

\section{Statistical analysis}

The data are expressed as the mean \pm SEM. The statistical significance of differences was assessed by ANOVA; a value of $P<0.05$ was considered statistically significant.

\section{Results}

Ezetimibe suppressed cholesterol accumulation in lipid-loaded VSMCs stimulated by Chol:M $\beta C D$

It is well known that cholesterol is involved in the pathogenesis of atherosclerosis. Excessive cholesterol accumulation in cells leads to the formation of foam cells, which is one of the hallmarks of atherosclerotic plaques within the arterial wall. In a previous study ${ }^{[31]}$, we successfully established a foam cell model by using $10 \mu \mathrm{g} / \mathrm{mL}$ Chol:M $\beta C D$, which is "water-soluble cholesterol" containing approximately $50 \mathrm{mg}$ of cholesterol per $g$ of solid (molar ratio, 1:6 cholesterol:M $\beta C D$ ) that delivers cholesterol rapidly and directly to the plasma membrane ${ }^{[32]}$. Using Oil Red O staining, we determined the morphological changes in cells after incubation of VSMC with Chol:M $\beta C D$ in the absence or presence of $3 \mu \mathrm{mol} / \mathrm{L}$ ezetimibe for $72 \mathrm{~h}$. Our results showed that ezetimibe treatment dramatically reduced cellular lipid accumulation in VSMCs treated with Chol:M $\beta C D$ (Figure 1). HPLC was then conducted to determine cellular cholesterol content. The concentrations of TC, FC and CE in ezetimibe-treated cells stimulated by Chol:M $\beta C D$ were significantly lower than those in the Chol:M $\beta C D$ group without ezetimibe treatment (Table 1). Thus, ezetimibe suppressed intracellular cholesterol accumulation effectively.
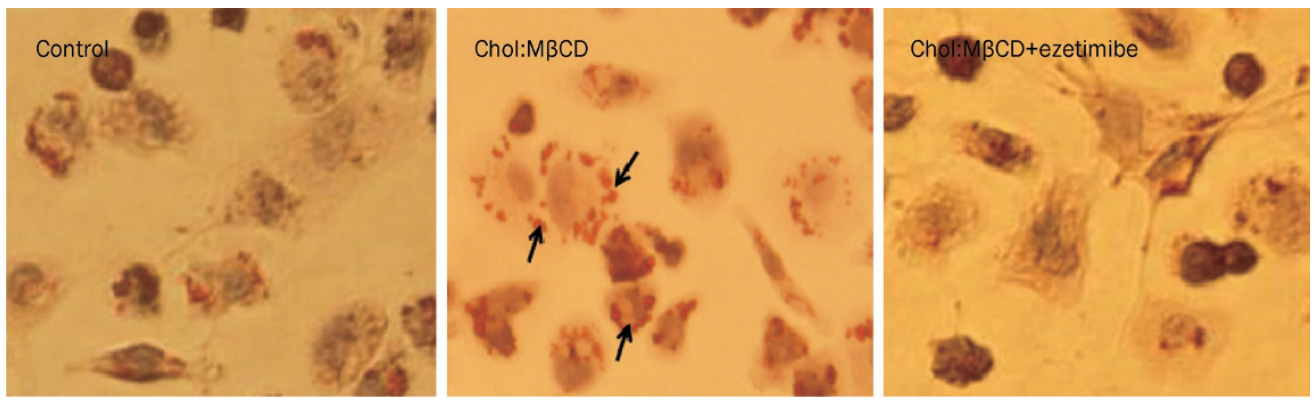

Figure 1. Effects of ezetimibe on cholesterol accumulation in lipid-loaded VSMCs induced by Chol:MBCD. VSMCs were co-incubated with 10 $\mu \mathrm{g} / \mathrm{mL}$ Chol:MBCD in the absence or presence of $3 \mu \mathrm{mol} / \mathrm{L}$ ezetimibe for $72 \mathrm{~h}$. After treatment, the cells were stained with Oil Red 0 . Cellular nuclei were stained with hematoxylin. The magnification of each panel is $\times 400$. All the results were obtained from 3 independent experiments, and each experiment was performed in triplicate. Arrows indicate the foam cells. 
Table 1. The effect of ezetimibe on cellular cholesterol content $(\mu \mathrm{g} / \mathrm{mg}$ protein). Intracellular lipid content in VSMCs. VSMCs were incubated with $10 \mu \mathrm{g} / \mathrm{mL}$ Chol:MBCD in the absence or presence of $3 \mu \mathrm{mol} / \mathrm{L}$ ezetimibe for $72 \mathrm{~h}$. Cholesterol ester (CE) and the ratio of CE/TC was calculated. The results are expressed as the mean $\pm \mathrm{SD}$ from 3 independent experiments, each performed in triplicate. ${ }^{c} P<0.01$ vs control. ${ }^{e} P<0.05$ vs Chol:MBCD.

\begin{tabular}{lcrrr}
\hline \multicolumn{1}{c}{ Group } & FC & TC & CE & CE/TC (\%) \\
\hline Control & & & & \\
Chol:M $\beta C D$ & $42.8 \pm 2.3$ & $47.5 \pm 3.1$ & $5.2 \pm 2.5$ & $11.2 \pm 2.1$ \\
Chol:M $B C D+$ ezetimibe & $85.2 \pm 5.1^{\circ}$ & $212.7 \pm 5.9^{\circ}$ & $112.8 \pm 9.2$ & $56.4 \pm 3.3$ \\
\hline
\end{tabular}

Ezetimibe downregulated SREBP-1 and upregulated Cav-1 protein expression in lipid-loaded VSMCs induced by Chol:M $\beta C D$ Caveolins, especially Cav-1, have been implicated in the regulation of cellular cholesterol metabolism and lipid uptake as well as cholesterol and lipid efflux ${ }^{[33]}$. It has been reported that Cav-1 is regulated by SREBP-1 due to SREBP-1 binding to the Cav-1 promoter. Therefore, we measured protein levels to determine whether Cav-1 and SREBP-1 are affected by ezetimibe. As shown in Figure $2 \mathrm{~A}$ and $2 \mathrm{~B}$, ezetimibe upregulated the expression of Cav-1 and downregulated the expression of
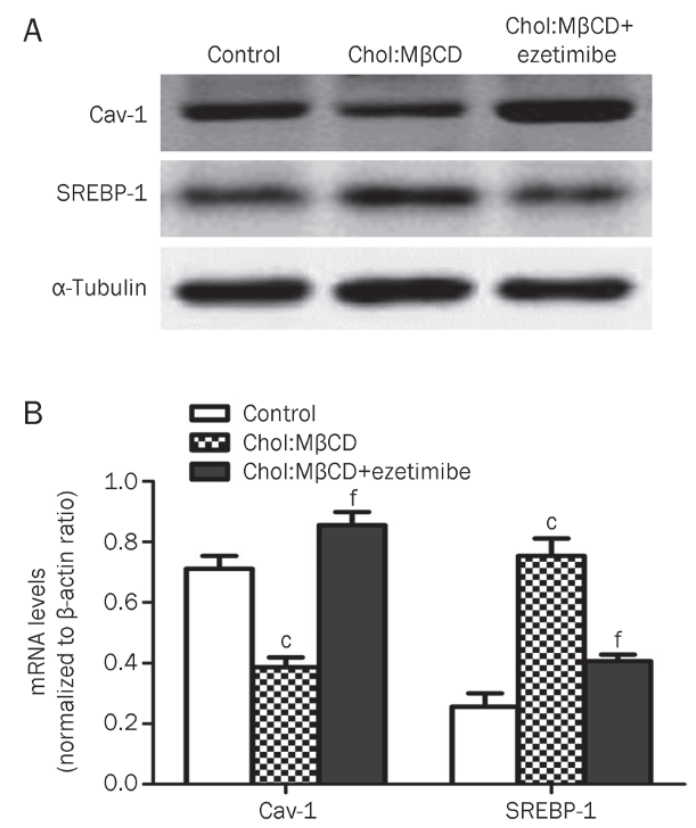

Figure 2. Effects of ezetimibe on the expression of Cav-1 and SREBP-1 in VSMCs in the presence of Chol:MBCD. (A) VSMCs were co-incubated with $10 \mu \mathrm{g} / \mathrm{mL}$ Chol:MBCD in the absence or presence of $3 \mu \mathrm{mol} / \mathrm{L}$ ezetimibe for $72 \mathrm{~h}$. Protein expression was detected by Western blot analysis (30 $\mu \mathrm{g}$ protein/lane). $\alpha$-Tubulin was used as a loading control. The data were obtained from three independent experiments. (B) VSMCs were co-incubated with $10 \mu \mathrm{g} / \mathrm{mL}$ Chol:MBCD in the absence or presence of $3 \mu \mathrm{mol} / \mathrm{L}$ ezetimibe for $72 \mathrm{~h}$. mRNA levels were evaluated by real-time quantitative polymerase chain reaction (PCR). The data were obtained from three independent experiments. ${ }^{c} P<0.01$ vs control. ${ }^{f} P<0.01$ vs Chol:MBCD.
SREBP-1 in VSMCs in the presence of Chol:M $\beta C D$ at both the protein and mRNA levels. These data indicate that the inhibitory effect of ezetimibe on cholesterol accumulation is most likely linked to the enhancement of Cav-1 expression and reduction of SREBP-1 expression.

Ezetimibe inhibited the nuclear translocation of SREBP-1 in lipidloaded VSMCs induced by Chol:M $\beta C D$

The SREBP-1 precursor is located on the membrane of the endoplasmic reticulum. When the intracellular cholesterol level changes, active SREBP-1 is transferred into the nucleus to regulate Cav-1 transcription ${ }^{[34]}$. To examine the activity of SREBP-1 under ezetimibe treatment, we observed SREBP-1 translocation by double immunofluorescence staining. Compared with the control group, Chol:M $\beta C D$ stimulated SREBP-1 translocation from the cytoplasm into the nucleus (Figure 3). However, there was a redistribution of SREBP-1 after ezetimibe treatment. A substantial portion of SREBP-1 accumulated in the cytoplasm after ezetimibe treatment, suggesting that ezetimibe reversed the process of SREBP-1 nuclear translocation (Figure 3).

\section{Ezetimibe regulates MAPK signaling in lipid-loaded VSMCs induced by Chol:M $\beta C D$}

It was reported that cholesterol exerts regulatory effects on receptor tyrosine kinase-mediated signaling and activated ERK $1 / 2^{[35]}$. Depletion of membrane cholesterol increases the phosphorylation of ERK ${ }^{[36,37]}$, which indicates that ERK1/2 activity is closely related to cellular cholesterol trafficking.

We next investigated whether ezetimibe had any effects on the activity and expression of ERK1/2. As shown in Figure $4 \mathrm{~A}$, ezetimibe regulated the expression of Cav-1 and SREBP-1 in a dose-dependent manner. It dose-dependently reduced the levels of $\mathrm{p}$-ERK1/2. Immunofluorescence analysis showed that treatment with Chol:M $\beta C D$ led to increased ERK1/2 in the nuclei compared to the control group (without either Chol:M $\beta C D$ or ezetimibe treatment), indicating the translocation of ERK1/2 into the nuclei. Nevertheless, the nuclear translocation of ERK1/2 stimulated by Chol:M $\beta C D$ could be abolished when cells were co-incubated with ezetimibe and Chol:M $\beta C D$ (Figure 4B). These observations are in agreement with the capability of ezetimibe to inhibit the Chol:M $\beta C D$ stimulated enhancement of p-ERK1/2 expression (Figure 4D).

To further explore whether the suppressive effect of ezetimibe on intracellular cholesterol accumulation involves ERK1/2 signaling, we utilized the MAPK inhibitor PD98059, which mainly blocks the ERK1/2 pathway. As shown in Figure $4 \mathrm{C}$, ezetimibe reduced the cellular lipid accumulation in lipid-loaded cells. Interestingly, a similar effect occurs in the PD98059 and Chol:M $\beta C D$ treatment group. The hypolipidemic effects of ezetimibe was not changed after addition of PD98059. These results indicated that the suppressive effect on intracellular cholesterol of ezetimibe may be associated with ERK1/2 pathway. Furthermore, PD98059 and ezetimibe markedly decreased the protein expression of $\mathrm{p}$-ERK1/2 and SREBP-1 while promoting Cav-1 expression in lipid-loaded 

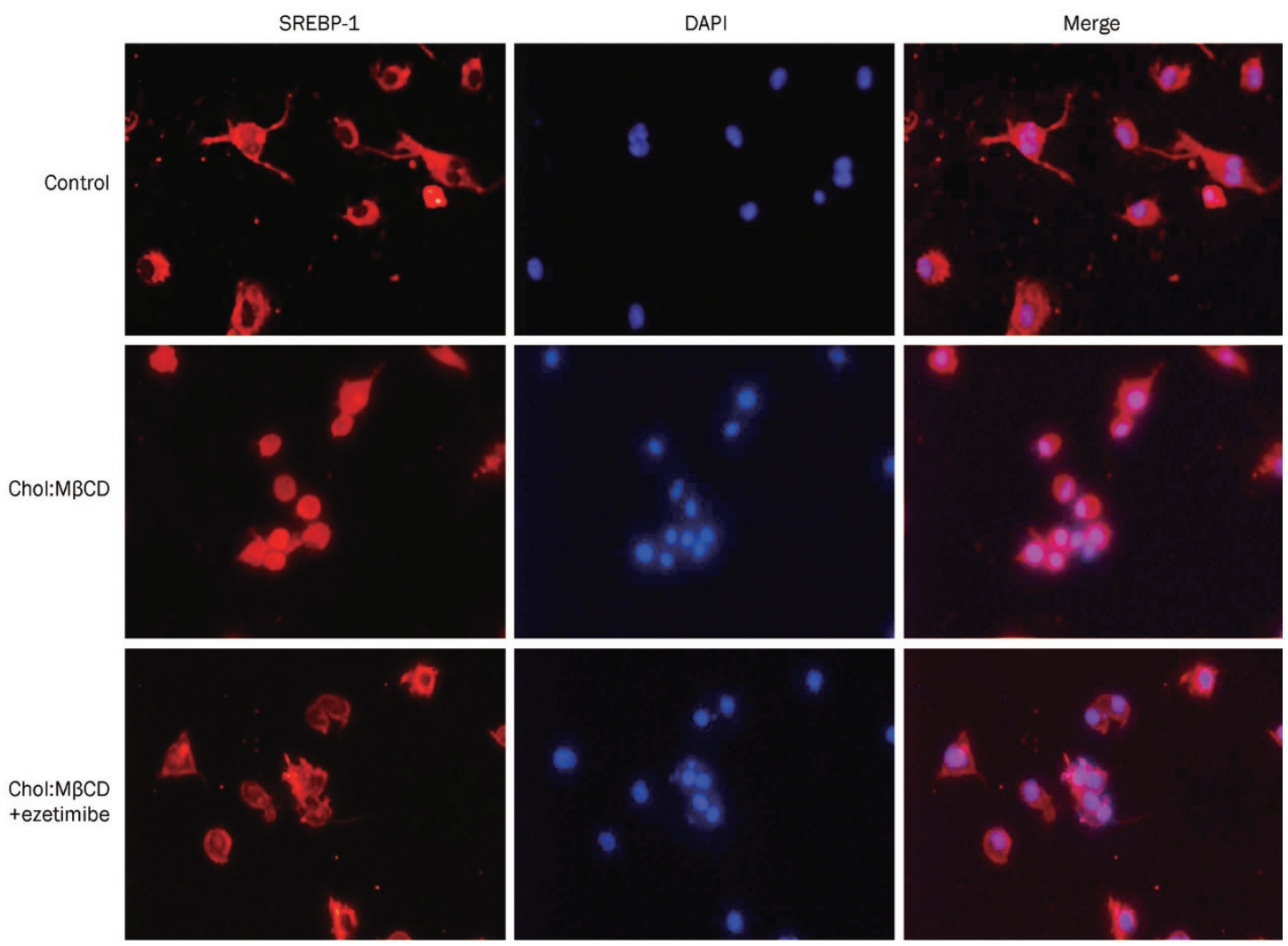

Figure 3. Effects of ezetimibe on nuclear translocation of SREBP-1 in lipid-loaded VSMCs induced by Chol:MBCD. VSMCs were co-incubated with $10 \mu \mathrm{g} / \mathrm{mL}$ Chol:MBCD in the absence or presence of $3 \mu \mathrm{mol} / \mathrm{L}$ ezetimibe for $72 \mathrm{~h}$. SREBP-1 in the cytoplasm (red) or nucleus (blue) was detected by indirect immunofluorescence with double staining. Images were obtained with a fluorescence microscope $(\times 400)$.

cells stimulated by Chol:M $\beta C D$ compared with the group treated with Chol:M $\beta C D$ alone. More importantly, the inhibitory effects of ezetimibe on the expression of p-ERK1/2 and SREBP-1 were enhanced after addition of PD98059 (Figure $4 \mathrm{D})$. Collectively, these results indicate that the ERK1/2 pathway is involved in the regulation of Cav- 1 and SREBP-1 by ezetimibe in VSMCs.

\section{Discussion}

The formation of VSMC- or macrophage-derived foam cells is a key pathologic process in atherosclerosis. It is believed that controlling the balance of cholesterol transport is strongly associated with regulation of atherosclerosis. In foam cells, the ratio of cholesterol ester (CE) in total cholesterol (TC) is more than $50 \%$, while VSMCs are referred to as lipid-loaded cells if the ratio is less than $50 \%{ }^{[12]}$. In our study, the intracellular $\mathrm{CE} / \mathrm{TC}$ ratio exceeded $50 \%$ when VSMCs were treated with $10 \mu \mathrm{g} / \mathrm{mL}$ Chol:M $\beta C D$ for $72 \mathrm{~h}$, while ezetimibe decreased the intracellular CE/TC ratio dramatically. Our findings clearly demonstrated that ezetimibe suppressed intracellular cholesterol accumulation effectively. Clinically, ezetimibe has been used in hypercholesterolemia for cholesterol reduction ${ }^{[38,39]}$. Therefore, our findings are consistent with the observations in clinical practice.

To date, stimulating cholesterol removal from lipid-loaded cells is believed to be a promising strategy to delay atherosclerosis. The accumulation of intracellular cholesterol is associated with an imbalance in cholesterol influx and efflux. Cav-1 plays a key role in cholesterol efflux in the form of an intracellular trafficking complex containing Cav-1, HSP56, cyclophilin $\mathrm{A}$ and cyclophilin $40^{[40]}$. In the present study, we found that ezetimibe could increase the level of the efflux-related protein Cav-1, suggesting that the suppressive effect of ezetimibe in cytoplasmic cholesterol accumulation might be due to the promotion of cholesterol efflux. Meanwhile, we also found that SREBP-1, a transcriptional regulator of Cav-1, was activated by Chol:M $\beta C D$. Active SREBP-1 translocates into the nucleus to regulate Cav-1 transcription via binding to two SREs in the promoter of Cav- $1^{[41]}$.

It has been shown that ezetimibe can effectively alter the transcription of some surface receptors (eg, NPC1L1) by downregulating the gene expression of the nuclear receptors SREBP-1 and SREBP-2 in Caco-2 cells ${ }^{[42]}$. Our results showed that Chol:M $\beta C D$-induced elevation of SREBP-1 and translocation of SREBP-1 from the cytoplasm into the nucleus could be inhibited by ezetimibe. ERK1/2 and p44/42 mitogen-activated protein kinases (p44/42 MAPK) belong to a highly conserved family of Ser-Thr protein kinases. The role of ERK1/2 in the development of atherosclerosis was described in a previous study ${ }^{[43]}$. Inhibition of ERK1/2 significantly increases 

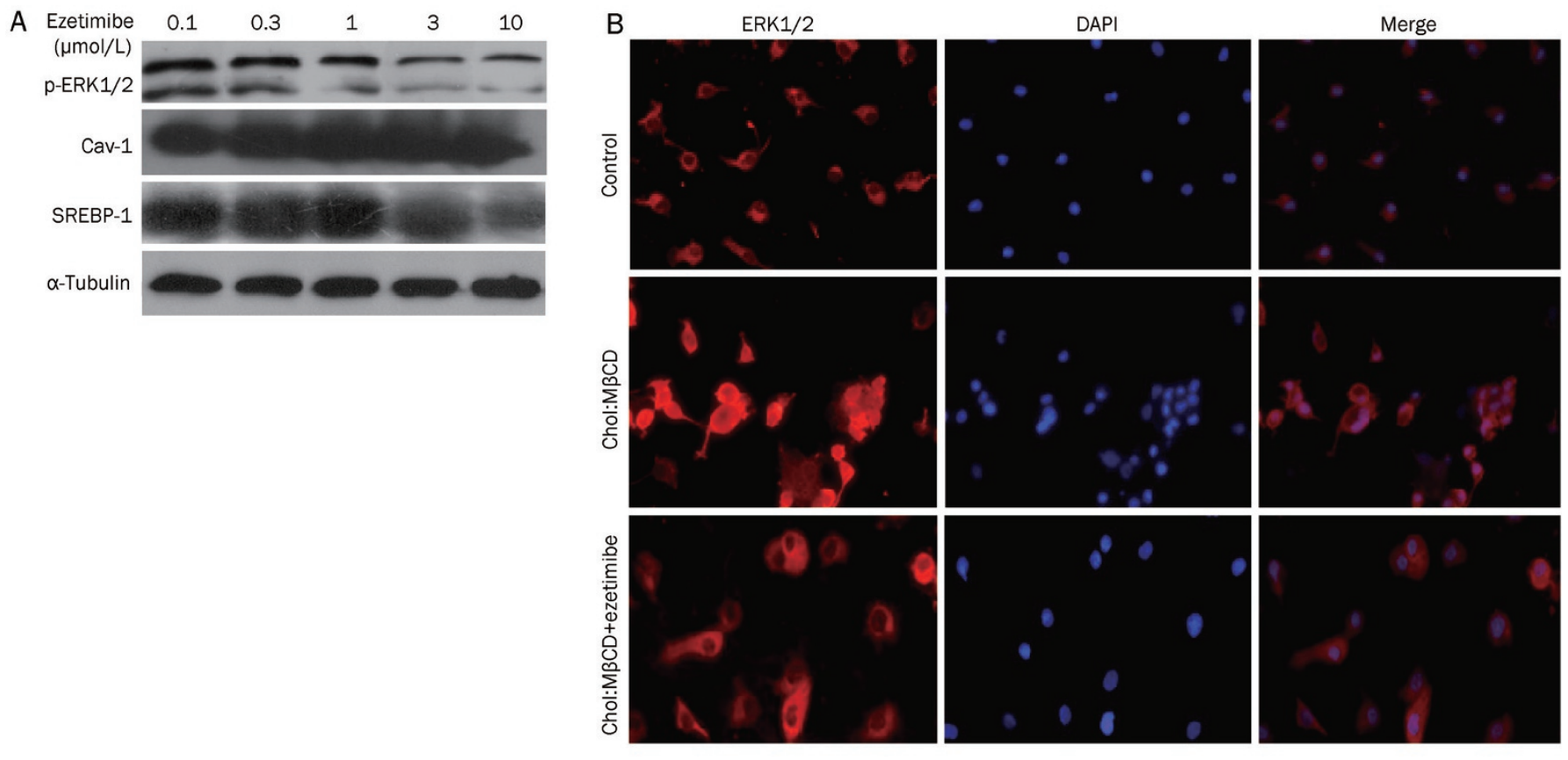

C

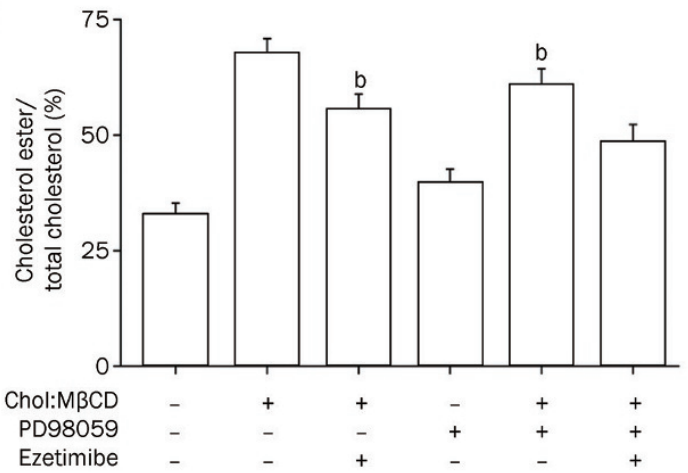

D

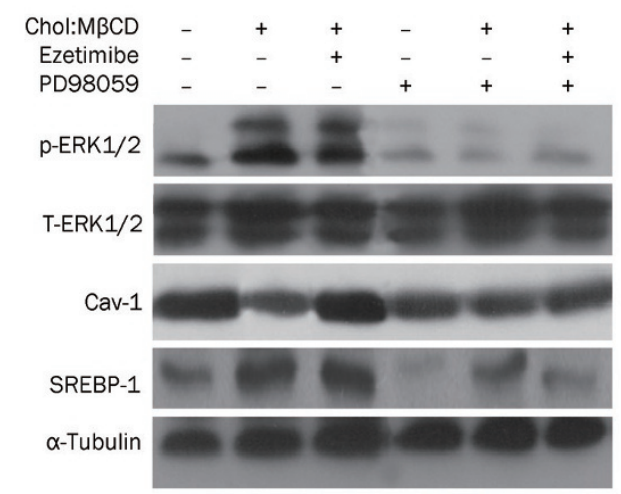

Figure 4. Ezetimibe regulates MAPK signaling in lipid-loaded VSMCs induced by Chol:MBCD. (A) The expression of p-ERK1/2, Cav-1, SREBP-1, and $\alpha$-tubulin was detected by Western blot analysis in VSMCs treated with ezetimibe at the indicated concentration in the presence of $10 \mu \mathrm{g} / \mathrm{mL} \mathrm{Chol}: \mathrm{M} \beta C D$ for $72 \mathrm{~h}$. (B) VSMCs were co-incubated with $10 \mu \mathrm{g} / \mathrm{mL}$ Chol:MBCD in the absence or presence of $3 \mu \mathrm{mol} / \mathrm{L}$ ezetimibe for $72 \mathrm{~h}$. The localization of p-ERK1/2 (red) was determined by immunofluorescence. Nuclei were stained with DAPI (blue). (C) VSMCs were incubated with or without $3 \mu$ mol/L ezetimibe for $72 \mathrm{~h}$ in the presence of $10 \mu \mathrm{g} / \mathrm{mL}$ Chol:MBCD followed by treatment with the ERK1/2 inhibitor PD98059 (50 $\mu \mathrm{mol} / \mathrm{L})$ for $1 \mathrm{~h}$. $n=3$. Mean \pm SEM. ${ }^{b} P<0.05$ vs $10 \mu \mathrm{g} / \mathrm{mL}$ Chol:MBCD group. (D) VSMCs were incubated with or without $3 \mu \mathrm{mol} / \mathrm{L}$ ezetimibe for $72 \mathrm{~h}$ in the presence of 10

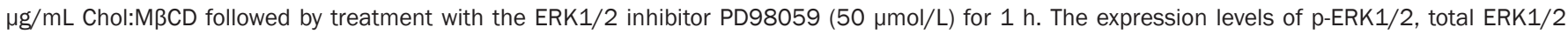
(T-ERK1/2), Cav-1, SREBP-1, and $\alpha$-tubulin were measured by Western blot analysis. $\alpha$-Tubulin served as a control. The data were obtained from three independent experiments.

cellular cholesterol efflux, which suggests that ERK1/2 activity is closely linked to cholesterol trafficking ${ }^{[43]}$. Once phosphorylated, ERK becomes an active kinase that translocates to the nucleus, where it has been shown to regulate the transcription of target genes. Moreover, the MAP kinase pathway appears to be critical for SREBP-1 stimulation in skeletal muscle ${ }^{[44]}$. Evidence from several studies has shown that SREBPs are substrates for ERK1 as well as ERK2 in vitro ${ }^{[45,46]}$. Furthermore, SREBP-1 is phosphorylated by the ERK subfamily of MAP kinases at serine 117.

As mentioned above, Muller-Wieland and co-workers ${ }^{[45]}$ demonstrated a strong linkage between the MAP kinasedependent pathway and expression of SREBP-1. In the present study, ezetimibe downregulated p-ERK1/2 expression in a dose-dependent manner, and a similar suppressive effect of ezetimibe on SREBP-1 expression was noted. More importantly, ezetimibe provoked a redistribution of SREBP-1 and ERK1/2, and the nuclear accumulation of ERK1/2 and SREBP-1 stimulated by Chol:M $\beta C D$ was reversed by ezetimibe in VSMCs. Furthermore, the inhibitory effects of ezetimibe on the expression of $p$-ERK1/2 and SREBP-1 were enhanced after addition of PD98059. These findings indicate that the effects of 
ezetimibe on the regulation of Cav-1 and SREBP-1 expression involve MAPK signaling.

In summary, ezetimibe strongly suppresses the intracellular accumulation of cholesterol by regulating the expression of SREBP-1 and Cav-1 via the MAPK pathway. Our study has revealed a novel mechanism underlying the anti-atherosclerosis properties of ezetimibe, which may aid the discovery of novel targets for anti-atherosclerosis therapy.

\section{Acknowledgements}

This work was supported by grants from the National Natural Science Foundation of China (№ 81000946, № 81270359, No 81173047, and No 12JJ5068) and the Construct Program of the Pharmaceutical Science Key Discipline in Hunan province.

\section{Author contribution}

All authors have made substantial contributions to this paper. Dr Duan-fang LIAO conceived and designed the current study and approved the final submitted version of the manuscript. Dr Li QIN and Yun-bo YANG performed a majority of the experiments and drafted the article. Dr Yi-xin YANG performed cell culture. Neng ZHU performed the HPLC assays. Ms Yong-zhen GONG and Dr Shun-xiang LI performed the immunofluorescence staining experiments. Dr Cai-ping ZHANG performed the matic fluorescence Assays.

\section{References}

1 Yan P, Xia C, Duan C, Li S, Mei Z. Biological characteristics of foam cell formation in smooth muscle cells derived from bone marrow stem cells. Int J Biol Sci 2011; 7: 937-46.

2 Sudhop T, Lutjohann D, Kodal A, Igel M, Tribble DL, Shah S, et al. Inhibition of intestinal cholesterol absorption by ezetimibe in humans. Circulation 2002; 106: 1943-8.

3 Tsunoda T, Nozue T, Yamada M, Mizuguchi I, Sasaki M, Michishita I. Effects of ezetimibe on atherogenic lipoproteins and glucose metabolism in patients with diabetes and glucose intolerance. Diabetes Res Clin Pract 2013; 100: 46-52.

4 Davis HR Jr, Lowe RS, Neff DR. Effects of ezetimibe on atherosclerosis in preclinical models. Atherosclerosis 2011; 215: 266-78.

5 Davis HR Jr, Compton DS, Hoos L, Tetzloff G. Ezetimibe, a potent cholesterol absorption inhibitor, inhibits the development of atherosclerosis in ApoE knockout mice. Arterioscler Thromb Vasc Biol 2001; 21: 2032-8.

6 Gomez-Garre D, Munoz-Pacheco P, Gonzalez-Rubio ML, Aragoncillo P, Granados R, Fernandez-Cruz A. Ezetimibe reduces plaque inflammation in a rabbit model of atherosclerosis and inhibits monocyte migration in addition to its lipid-lowering effect. Br J Pharmacol 2009; 156: 1218-27.

7 Rothberg KG, Heuser JE, Donzell WC, Ying YS, Glenney JR, Anderson RG. Caveolin, a protein component of caveolae membrane coats. Cell 1992; 68: 673-82.

8 Pavlides S, Gutierrez-Pajares JL, Danilo C, Lisanti MP, Frank PG. Atherosclerosis, caveolae and caveolin-1. Adv Exp Med Biol 2012; 729: $127-44$.

9 Chang SH, Feng D, Nagy JA, Sciuto TE, Dvorak AM, Dvorak HF. Vascular permeability and pathological angiogenesis in caveolin-1-null mice. Am J Pathol 2009; 175: 1768-76.

10 Drab M, Verkade P, Elger M, Kasper M, Lohn M, Lauterbach B, et al.
Loss of caveolae, vascular dysfunction, and pulmonary defects in caveolin-1 gene-disrupted mice. Science 2001; 293: 2449-52.

$11 \mathrm{Hu}$ Q, Zhang XJ, Liu CX, Wang XP, Zhang Y. PPARgamma1-induced caveolin-1 enhances cholesterol efflux and attenuates atherosclerosis in apolipoprotein E-deficient mice. J Vasc Res 2010; 47: 69-79.

12 Luo DX, Cao DL, Xiong Y, Peng XH, Liao DF. A novel model of cholesterol efflux from lipid-loaded cells. Acta Pharmacol Sin 2010; 31: 1243-57.

13 Smart EJ, De Rose RA, Farber SA. Annexin 2-caveolin 1 complex is a target of ezetimibe and regulates intestinal cholesterol transport. Proc Natl Acad Sci U S A 2004; 101: 3450-5.

14 De Rose RA, Farber SA. Retraction for Smart et al. Annexin 2-caveolin 1 complex is a target of ezetimibe and regulates intestinal cholesterol transport. Proc Natl Acad Sci U S A 2013; 110: 797.

15 Bennett MK, Seo YK, Datta S, Shin DJ, Osborne TF. Selective binding of sterol regulatory element-binding protein isoforms and co-regulatory proteins to promoters for lipid metabolic genes in liver. J Biol Chem 2008; 283: 15628-37.

16 During A, Dawson HD, Harrison EH. Carotenoid transport is decreased and expression of the lipid transporters SR-BI, NPC1L1, and ABCA1 is downregulated in Caco-2 cells treated with ezetimibe. J Nutr 2005; 135: 2305-12.

17 Horton JD, Goldstein JL, Brown MS. SREBPs: activators of the complete program of cholesterol and fatty acid synthesis in the liver. J Clin Invest 2002; 109: 1125-31.

18 Daemen S, Kutmon M, Evelo CT. A pathway approach to investigate the function and regulation of SREBPs. Genes Nutr 2013; 8: 289300.

19 Luo DX, Xia CL, Li JM, Xiong Y, Yuan HY, Tang ZW, et al. Static pressure accelerates ox-LDL-induced cholesterol accumulation via SREBP-1mediated caveolin-1 downregulation in cultured vascular smooth muscle cells. Biochem Biophys Res Commun 2010; 403: 52-8.

20 Yuan HY, Kuang SY, Zheng X, Ling HY, Yang YB, Yan PK, et al. Curcumin inhibits cellular cholesterol accumulation by regulating SREBP-1/caveolin-1 signaling pathway in vascular smooth muscle cells. Acta Pharmacol Sin 2008; 29: 555-63.

21 Muraoka T, Aoki K, Iwasaki T, Shinoda K, Nakamura A, Aburatani H, et al. Ezetimibe decreases SREBP-1c expression in liver and reverses hepatic insulin resistance in mice fed a high-fat diet. Metabolism 2011; 60: 617-28.

22 Mulay V, Wood P, Manetsch M, Darabi M, Cairns R, Hoque M, et al. Inhibition of mitogen-activated protein kinase Erk1/2 promotes protein degradation of ATP binding cassette transporters A1 and G1 in $\mathrm{CHO}$ and $\mathrm{HuH} 7$ cells. PLoS One 2013; 8: e62667.

23 Roth G, Kotzka J, Kremer L, Lehr S, Lohaus C, Meyer HE, et al. MAP kinases Erk1/2 phosphorylate sterol regulatory element-binding protein (SREBP)-1a at serine 117 in vitro. J Biol Chem 2000; 275: 33302-7.

24 Qin L, Zhang X, Zhang L, Feng Y, Weng GX, Li MZ, et al. Downregulation of $\mathrm{BMI}-1$ enhances 5 -fluorouracil-induced apoptosis in nasopharyngeal carcinoma cells. Biochem Biophys Res Commun 2008; 371: 531-5.

25 Yang M, Huang HL, Zhu BY, Tuo QH, Liao DF. Onychin inhibits proliferation of vascular smooth muscle cells by regulating cell cycle. Acta Pharmacol Sin 2005; 26: 205-11.

26 Keramati AR, Singh R, Lin A, Faramarzi S, Ye ZJ, Mane S, et al. Wildtype LRP6 inhibits, whereas atherosclerosis-linked LRP6R611C increases PDGF-dependent vascular smooth muscle cell proliferation. Proc Natl Acad Sci U S A 2011; 108: 1914-8.

27 Sun SW, Zu XY, Tuo QH, Chen LX, Lei XY, Li K, et al. Caveolae and caveolin-1 mediate endocytosis and transcytosis of oxidized low 
density lipoprotein in endothelial cells. Acta Pharmacol Sin 2010; 31: 1336-42.

28 Wang QQ, Zhang ZY, Xiao JY, Yi C, Li LZ, Huang Y, et al. Knockdown of nucleophosmin induces S-phase arrest in HepG2 cells. Chin J Cancer 2011; 30: 853-60.

29 Qin L, Yang YB, Tuo QH, Zhu BY, Chen LX, Zhang L, et al. Effects and underlying mechanisms of curcumin on the proliferation of vascular smooth muscle cells induced by Chol:MbetaCD. Biochem Biophys Res Commun 2009; 379: 277-82.

30 Zheng FJ, Ye HB, Wu MS, Lian YF, Qian CN, Zeng YX. Repressing malic enzyme 1 redirects glucose metabolism, unbalances the redox state, and attenuates migratory and invasive abilities in nasopharyngeal carcinoma cell lines. Chin J Cancer 2012; 31: 519-31.

31 Rong JX, Shapiro M, Trogan E, Fisher EA. Transdifferentiation of mouse aortic smooth muscle cells to a macrophage-like state after cholesterol loading. Proc Natl Acad Sci U S A 2003; 100: 13531-6.

32 Christian AE, Haynes MP, Phillips MC, Rothblat GH. Use of cyclodextrins for manipulating cellular cholesterol content. J Lipid Res 1997; 38: 2264-72.

33 Frank PG. Endothelial caveolae and caveolin-1 as key regulators of atherosclerosis. Am J Pathol 2010; 177: 544-6.

34 Brown AJ, Sun L, Feramisco JD, Brown MS, Goldstein JL. Cholesterol addition to ER membranes alters conformation of SCAP, the SREBP escort protein that regulates cholesterol metabolism. Mol Cell 2002; 10: $237-45$.

35 Ringerike T, Blystad FD, Levy FO, Madshus IH, Stang E. Cholesterol is important in control of EGF receptor kinase activity but EGF receptors are not concentrated in caveolae. J Cell Sci 2002; 115: 1331-40.

36 Wang PY, Liu P, Weng J, Sontag E, Anderson RG. A cholesterolregulated PP2A/HePTP complex with dual specificity ERK1/2 phosphatase activity. EMBO J 2003; 22: 2658-67.

37 Wang PY, Weng J, Anderson RG. OSBP is a cholesterol-regulated scaffolding protein in control of ERK $1 / 2$ activation. Science 2005;
307: 1472-6.

38 Pandor A, Ara RM, Tumur I, Wilkinson AJ, Paisley S, Duenas A, et al. Ezetimibe monotherapy for cholesterol lowering in 2722 people: systematic review and meta-analysis of randomized controlled trials. J Int Med 2009; 265: 568-80.

39 Katsiki N, Theocharidou E, Karagiannis A, Athyros VG, Mikhailidis DP. Ezetimibe therapy for dyslipidemia: an update. Curr Pharm Design 2013; 19: 3107-14.

40 Uittenbogaard A, Smart EJ. Palmitoylation of caveolin-1 is required for cholesterol binding, chaperone complex formation, and rapid transport of cholesterol to caveolae. J Biol Chem 2000; 275: 25595-9.

41 Bist A, Fielding PE, Fielding CJ. Two sterol regulatory element-like sequences mediate up-regulation of caveolin gene transcription in response to low density lipoprotein free cholesterol. Proc Natl Acad Sci U S A 1997; 94: 10693-8.

42 Alrefai WA, Annaba F, Sarwar Z, Dwivedi A, Saksena S, Singla A, et al. Modulation of human Niemann-Pick C1-like 1 gene expression by sterol: Role of sterol regulatory element binding protein 2. Am J Physiol Gastrointest Liver Physiol 2007; 292: G369-76.

43 Zhou X, Yin Z, Guo X, Hajjar DP, Han J. Inhibition of ERK1/2 and activation of liver $X$ receptor synergistically induce macrophage ABCA1 expression and cholesterol efflux. J Biol Chem 2010; 285: 6316-26.

44 Shimomura I, Matsuda M, Hammer RE, Bashmakov Y, Brown MS, Goldstein JL. Decreased IRS-2 and increased SREBP-1c lead to mixed insulin resistance and sensitivity in livers of lipodystrophic and $o b / o b$ mice. Mol Cell 2000; 6: 77-86.

45 Kotzka J, Muller-Wieland D, Roth G, Kremer L, Munck M, Schurmann $\mathrm{S}$, et al. Sterol regulatory element binding proteins (SREBP)-1a and SREBP-2 are linked to the MAP-kinase cascade. J Lipid Res 2000; 41: 99-108.

46 Davis RJ. The mitogen-activated protein kinase signal transduction pathway. J Biol Chem 1993; 268: 14553-6. 